\title{
Optical-active phonons in $\mathrm{A}_{3} \mathrm{Fe}_{2} \mathrm{~B}^{\prime \prime} \mathrm{O}_{9}\left(\mathrm{~A}=\mathrm{Ca}, \mathrm{Sr}\right.$; $\left.\mathrm{B}^{\prime \prime}=\mathrm{Te}, \mathrm{W}\right)$ double perovskites
}

\author{
E. N. Silva, ${ }^{1, a)}$ I. Guedes, ${ }^{2}$ A. P. Ayala, ${ }^{2}$ C. A. López, ${ }^{3}$ M. S. Augsburger, ${ }^{3}$ M. del C. Viola, ${ }^{3}$ \\ and J. C. Pedregosa ${ }^{3}$ \\ ${ }^{1}$ Departamento de Física, Universidade Federal do Maranhão, 65085-580, São Luis-MA-Brazil \\ ${ }^{2}$ Departamento de Física, Universidade Federal do Ceará, Caixa Postal 6030, 60475-970, Fortaleza, \\ Ceará, Brazil \\ ${ }^{3}$ Área de Química General e Inorgánica "Dr. G. F. Puelles," Departamento de Química, Facultad de \\ Química, Bioquímica y Farmacia, Universidad Nacional de San Luis, San Luis, Argentina
}

(Received 1 October 2009; accepted 6 January 2010; published online 22 February 2010)

\begin{abstract}
Raman scattering and infrared transmittance techniques are used to investigate the phonons of the $\mathrm{Sr}_{3} \mathrm{Fe}_{2} \mathrm{TeO}_{9}$ (SFTO), $\mathrm{Sr}_{3} \mathrm{Fe}_{2} \mathrm{WO}_{9}$ (SFWO), and $\mathrm{Ca}_{3} \mathrm{Fe}_{2} \mathrm{WO}_{9}$ (CFWO) double perovskites at $300 \mathrm{~K}$. While SFTO and SFWO crystallize in a tetragonal structure belonging to the $I 4 / \mathrm{m}$ space with two formulas per unit cell $(\mathrm{Z}=2)$, CFWO crystallizes in a monoclinic structure belonging to the space group $P 2_{1} / n$ with $\mathrm{Z}=2$. The observed spectra are very similar to that of the prototype cubic $(F m \overline{3} m)$ double perovskite, indicating that both the tetragonal and monoclinic structures result from small distortions of the cubic cell. The assignment of the optical phonons follows that given for the prototype $F m \overline{3} m$ double perovskites. (C) 2010 American Institute of Physics.

[doi:10.1063/1.3309259]
\end{abstract}

\section{INTRODUCTION}

Ideal $\mathrm{ABO}_{3}$ perovskites crystallize in the cubic $P m \overline{3} m$ structure, exhibiting no active first-order Raman phonons. By doping the $\mathrm{B}$ symmetry sites the new stoichiometry reads $A B_{1-x}^{\prime} B_{x}^{\prime \prime} X_{3}$. If either the charge or the size of the $B^{\prime}$ and $B^{\prime \prime}$ cations are sufficiently different, an ordering at B symmetry sites may occur and the compound is commonly described as a double perovskite, whose stoichiometry is now properly written as $\mathrm{A}_{2} \mathrm{~B}^{\prime} \mathrm{B}^{\prime \prime} \mathrm{X}_{6}$. This structure can be described as a regular arrangement of corner-sharing $\mathrm{B}^{\prime} \mathrm{O}_{6}$ and $\mathrm{B}^{\prime \prime} \mathrm{O}_{6}$ alternating along the three crystallographic directions of the compound.

Both the ordered or disordered double perovskites exhibit interesting physical properties such as: superconductivity, magnetoresistivity, ferroelectricity, piezoelectricity, electron-phonon interactions, etc. ${ }^{1-9}$ Recently, the x-ray absorption and synchrotron radiation diffraction techniques were used to investigate the degree of disorder in polycrystalline $\mathrm{Sr}_{2} \mathrm{FeMoO}_{6}$ samples. ${ }^{10}$ It was observed, a very high degree of short range ordering even for samples presenting highly reduced long range chemical ordering.

The 1:1 ordering at B-site is the most common ordering arrangement. Recently, Howard et al. ${ }^{11}$ used the group theory method to enumerate the 12 different $\mathrm{A}_{2} \mathrm{~B}^{\prime} \mathrm{B}^{\prime \prime} \mathrm{X}_{6}$ structures which are compatible with all the possible octahedral tiltings.

The highest symmetry phase is cubic belonging to the $F m \overline{3} m$ space group, whose optical-active phonon distribution is $\mathrm{A}_{1 \mathrm{~g}}+\mathrm{E}_{\mathrm{g}}+2 \mathrm{~F}_{2 \mathrm{~g}}+4 \mathrm{~F}_{1 \mathrm{u}}$. Small changes in the tilting of the $\mathrm{BO}_{6}$ octahedra lead to either a tetragonal or monoclinic distortion, as observed for $\mathrm{Sr}_{2}[\mathrm{Co}]^{2 \mathrm{a}}[\mathrm{Mo}]^{2 \mathrm{~b}} \mathrm{O}_{6}$ (Ref. 12) and $\mathrm{Ca}_{2}[\mathrm{Co}]^{2 \mathrm{c}}[\mathrm{Te}]^{2 \mathrm{~d}} \mathrm{O}_{6},{ }^{13}$ respectively.

\footnotetext{
${ }^{a)}$ Electronic mail: silvaen@gmail.com. Tel.: 2109-8204. FAX: 2109-8204.
}

Besides the 1:1 ordering at the B-sites, other orderings are also possible. For instance, the $2: 1$ ordering leads to the stoichiometry $\mathrm{A}_{3} \mathrm{~B}_{2}^{\prime} \mathrm{B}^{\prime \prime} \mathrm{X}_{9}$. This is the case for $\mathrm{A}_{3} \mathrm{CaRu}_{2} \mathrm{O}_{9}$ $(\mathrm{A}=\mathrm{Sr} \text { and } \mathrm{Ba})^{14,15}$ and $\mathrm{Ba}_{3} \mathrm{ZnTa}_{2} \mathrm{O}_{9},{ }^{16}$ whose crystal structures are described by a trigonal system belonging to the $\mathrm{P} \overline{3} \mathrm{~m} 1$ space group, where the $\mathrm{B}^{\prime}$ and $\mathrm{B}^{\prime \prime}$ cations are located at the Wyckoff's $1 \mathrm{~b}$ and $2 \mathrm{~d}$ positions, respectively. In this case, there is no occupational disorder at the octahedral symmetry sites.

However, some $A_{3} B_{2}^{\prime} B^{\prime \prime} X_{9}$ perovskites exhibit a $1: 1$ ordering at $\mathrm{B}^{\prime \prime}$-sites. In this case, an intrinsic occupational disorder is observed and the stoichiometry is better described as $\mathrm{A}_{2} \mathrm{~B}^{\prime}\left(\mathrm{B}_{1 / 3}^{\prime} \mathrm{B}_{2 / 3}^{\prime \prime}\right) \mathrm{O}_{6}$. If the $\mathrm{B}^{\prime}$-sites are also disorderly occupied the stoichiometry reads $\mathrm{A}_{2}\left(\mathrm{~B}_{1-\mathrm{x}}^{\prime} \mathrm{B}_{\mathrm{x}}^{\prime \prime}\right)\left(\mathrm{B}_{1 / 3+\mathrm{x}}^{\prime} \mathrm{B}_{2 / 3-\mathrm{x}}^{\prime \prime}\right) \mathrm{O}_{6}$.

Raman and infrared spectroscopy provide valuable insight into order-disorder phenomena and are very sensitive to sample composition and structural variations, making it suitable for studying the effects of atomic substitutions in complex perovskites. $^{17-21}$

There has been an increasing interest in the study of $\mathrm{A}_{3} \mathrm{Fe}_{2} \mathrm{~B}^{\prime \prime} \mathrm{O}_{9} \quad\left(\mathrm{~A}=\mathrm{Ca}, \mathrm{Sr} ; \mathrm{B}^{\prime \prime}=\mathrm{Te}, \mathrm{W}\right)$ double perovskites, which exhibit exciting ferromagnetic properties at room temperature. ${ }^{2-7}$ The $\mathrm{Sr}_{3} \mathrm{Fe}_{2} \mathrm{WO}_{9}$ (SFWO) and $\mathrm{Ca}_{3} \mathrm{Fe}_{2} \mathrm{WO}_{9}$ (CFWO) compounds have been investigated by neutron powder diffraction by Ivanov et al., ${ }^{2,3}$ who determined that SFWO crystallizes at $300 \mathrm{~K}$ in a tetragonal structure belonging to the space group $I 4 / \mathrm{m}$, while CFWO crystallizes in a monoclinic structure belonging to the space group $P 2_{1} / n$. Identical results have been obtained for CFWO by Retuerto et $a .^{22}$ These compounds exhibit a partially ordered double perovskite structures, in which the $\mathrm{Fe}$ and $\mathrm{W}$ cations are orderly distributed at the $\mathrm{B}^{\prime}$ - and $\mathrm{B}^{\prime \prime}$-symmetry sites of the perovskite lattice. For SFWO (CFWO), the occupation of the $2 a$-site is $\quad 0.79 \mathrm{Fe}(1)^{3+}+0.21 \mathrm{~W}(1)^{6+} \quad\left[0.73 \mathrm{Fe}(1)^{3+}\right.$ 
$\left.+0.21 \mathrm{~W}(1)^{6+}\right]$, while the occupation of the $2 b$-sites is $0.54 \mathrm{Fe}(2)^{3+}+0.46 \mathrm{~W}(2)^{6+}\left(0.60 \mathrm{Fe}(2)^{3+}+0.40 \mathrm{~W}(2)^{6+}\right)$. So, it is more convenient to rewrite the stoichiometry of these compounds as $\mathrm{Sr}_{2}\left[\mathrm{Fe}_{0.79} \mathrm{~W}_{0.21}\right]^{2 \mathrm{a}}\left[\mathrm{Fe}_{0.54} \mathrm{~W}_{0.46}\right]^{2 \mathrm{~b}} \mathrm{O}_{6}$ and $\mathrm{Ca}_{2}\left[\mathrm{Fe}_{0.73} \mathrm{~W}_{0.27}\right]^{2 \mathrm{a}}\left[\mathrm{Fe}_{0.60} \mathrm{~W}_{0.40}\right]^{2 \mathrm{~b}} \mathrm{O}_{6}$ for SFWO and CFWO, respectively, where the superscripts stand for the Wyckoff's site symmetries. ${ }^{2,3}$ According to Augsburger et al. ${ }^{5}$ and Viola ${ }^{6}$ the Te-based compound, $\mathrm{Sr}_{3} \mathrm{Fe}_{2} \mathrm{TeO}_{9}$ (SFTO), also exhibits a tetragonal structure belonging to the space group $I 4 / \mathrm{m}$. In this case, the stoichiometry reads $\mathrm{Sr}_{2}\left[\mathrm{Fe}_{0.57} \mathrm{Te}_{0.43}\right]^{2 \mathrm{a}}\left[\mathrm{Fe}_{0.90} \mathrm{Te}_{0.10}\right]^{2 \mathrm{~b}} \mathrm{O}_{6}$. On the other hand Ivanov et al. $^{4}$ observed a minor cationic ordering with formula $\mathrm{Sr}_{2}\left[\mathrm{Fe}_{0.72} \mathrm{Te}_{0.28}\right]^{2 \mathrm{a}}\left[\mathrm{Fe}_{0.61} \mathrm{Te}_{0.39}\right]^{2 \mathrm{~b}} \mathrm{O}_{6}$.

In order to understand the degree of disorder of $\mathrm{A}_{3} \mathrm{Fe}_{2} \mathrm{~B}^{\prime \prime} \mathrm{O}_{9}\left(\mathrm{~A}=\mathrm{Ca}, \mathrm{Sr} ; \mathrm{B}^{\prime \prime}=\mathrm{Te}, \mathrm{W}\right)$ compounds here we use the Raman scattering and infrared (IR) transmittance techniques to record their room-temperature vibration spectra. The assignment proposed is based on that given for double perovskites with $F m \overline{3} m$ symmetry.

\section{EXPERIMENTAL}

Samples of SFWO, SFTO, and CFWO were prepared as polycrystalline powders by solid state reaction following the procedure described elsewhere. $^{2-6}$ The phase identification and characterization of the samples were carried out by x-ray powder diffraction (XRPD) (Cu $K \alpha=1.5418 \AA$ ) using a Rigaku D-MAX-IIIC diffractometer. Minor traces $(<1 \%)$ of parasitic phases were found. It was verified that the samples exhibit lower symmetry crystalline space groups derived from the prototype $F m \overline{3} m$ double perovskite structure. The good agreement between the observed and calculated XRPD patterns is shown in Fig. 1. This superstructure is associated with the doubling of the lattice parameter due to the $1: 1$

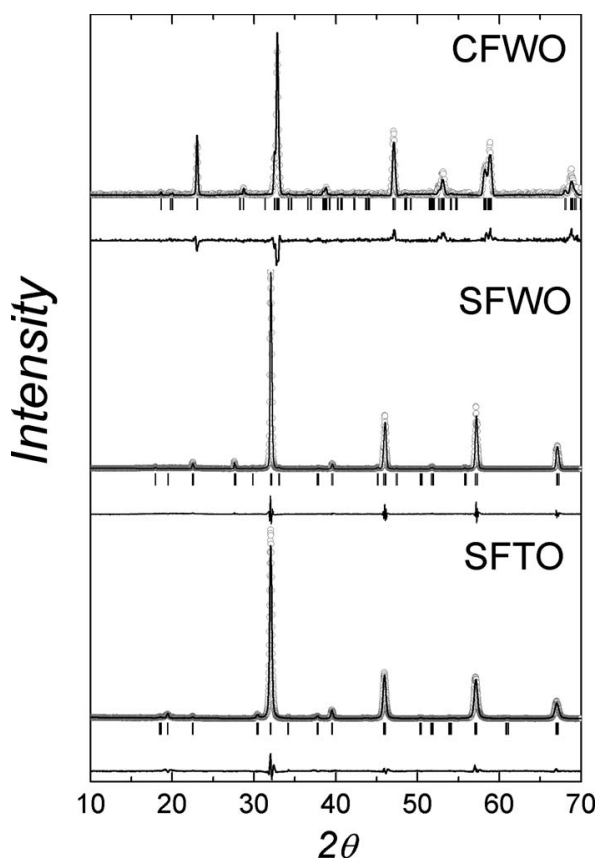

FIG. 1. Room-temperature XRPD patterns of the $\mathrm{A}_{3} \mathrm{Fe}_{2} \mathrm{WO}_{9}(\mathrm{~A}=\mathrm{Sr}, \mathrm{Ca})$ and SFTO double perovskites. Observed (circles), calculated (full line), and difference (bottom) profiles after refinement.
TABLE I. Crystallographic data of SFTO, SFWO, and CFWO. The 2a (000) and $2 \mathrm{~b}(001 / 2)$ [2a (1/201/2) and 2b (1/200)] subscripts refer to Wyckoff's site symmetries for tetragonal [monoclinic] structures, while $e q$ and $a p$ subscripts refer to equatorial and apical oxygen atoms, respectively.

\begin{tabular}{cccc}
\hline \hline & SFTO $(I 4 / m)^{\mathrm{a}}$ & ${\text { SFWO }(I 4 / m)^{\mathrm{b}}}^{\mathrm{C}}$ & $\mathrm{CFWO}\left(P 2_{1} / n\right)^{\mathrm{c}}$ \\
\hline $\mathrm{a}(\AA)$ & 5.5590 & 5.5784 & 5.4171 \\
$\mathrm{~b}(\AA)$ & 5.5590 & 5.5784 & 5.5084 \\
$\mathrm{c}(\AA)$ & 7.8850 & 7.8659 & 7.7002 \\
$\beta(\mathrm{deg})$ & 90.000 & 90.000 & 90.029 \\
$\phi[001]\left({ }^{\circ}\right)$ & 4.5 & 5 & 13 \\
$\psi[110]\left({ }^{\circ}\right)$ & 0 & 0 & 13 \\
$V\left(\AA^{3}\right)$ & 246 & 245 & 230 \\
$\langle\mathrm{~A}-\mathrm{O}\rangle_{e q}(\AA)$ & 2.786 & 2.788 & 2.764 \\
$\langle\mathrm{~A}-\mathrm{O}\rangle_{a p}(\AA)$ & 2.780 & 2.789 & 2.755 \\
$\left\langle\left(\mathrm{Fe} / \mathrm{B}^{\prime \prime}\right)_{2 a^{-}} O\right\rangle_{e q}(\AA)$ & 1.983 & 1.988 & 2.000 \\
$\left\langle\left(\mathrm{Fe} / \mathrm{B}^{\prime \prime}\right)_{2 a}-O\right\rangle_{a p}(\AA)$ & 1.908 & 1.927 & 1.984 \\
$\Delta d_{2 a}\left(\times 10^{-5}\right)$ & 37 & 24 & 2.25 \\
$\left\langle\left(\mathrm{Fe} / \mathrm{B}^{\prime \prime}\right)_{2 b}-O\right\rangle_{e q}(\AA)$ & 1.960 & 1.972 & 1.974 \\
$\left\langle\left(\mathrm{Fe} / \mathrm{B}^{\prime \prime}\right)_{2 b}-O\right\rangle_{a p}(\AA)$ & 2.034 & 2.006 & 1.970 \\
$\Delta d_{2 b}\left(\times 10^{-5}\right)$ & 35 & 7.21 & 1.28 \\
\hline \hline $\mathrm{Reference} 11$. &
\end{tabular}

${ }^{\mathrm{a}}$ Reference 11 .

${ }^{\mathrm{b}}$ Reference 9 .

${ }^{c}$ Reference 15 .

order of the $B$ cations. The crystallographic data are shown in Table I. The monoclinic space group $P 2_{1} / n$ requires that the $\mathrm{Fe}(1) / \mathrm{W}(1)$ and $\mathrm{Fe}(2) / \mathrm{W}(2)$ octahedra have different tilt angles due to the difference in the size and distortion of each polyhedron. $\phi$ and $\psi$ denotes the rotation around the [001] and [110] axes, respectively. The octahedron was quantified using the distortion index ${ }^{23}$

$$
\Delta d=\frac{1}{6} \sum_{n=1}^{6}\left(\frac{d_{n}}{\bar{d}}-1\right)^{2},
$$

where, $d_{n}$ and $\bar{d}$ are the individual and average $\mathrm{B}^{\prime \prime}-\mathrm{O}$ bond distances, respectively.

The IR transmission spectra were recorded between 2000 and $250 \mathrm{~cm}^{-1}$ with a Nicolet Protègè 460 Fourier transform infrared (FTIR) spectrometer with 32 scans, using the $\mathrm{KBr}$ pellet technique. The spectral resolution was $\pm 4 \mathrm{~cm}^{-1}$. All measurements were performed at room temperature.

The Raman spectra were recorded on a Jobin-Yvon T64000 triple-spectrometer instrument equipped with a $\mathrm{N}_{2}$-cooled charge coupled device. The spectra were taken in the backscattering configuration using a microscope equipped with a long working distance objective $(20 \times, 20$ $\mathrm{mm}$ ) and the $514.5 \mathrm{~nm}$ emission line of an $\mathrm{Ar}^{+}$laser (Innova 70, Coherent Inc.). The laser power on the sample surface was less than $50 \mathrm{~mW}$. The spectral slit widths were set for yielding a spectral resolution of $2 \mathrm{~cm}^{-1}$. All measurements were performed at room temperature.

\section{RESULTS AND DISCUSSION}

According to the crystallographic data both SFWO and SFTO belong to the tetragonal $I 4 / m(Z=2)$ space group, whereas CFWO belongs to the monoclinic $P 2_{1} / n \quad(\mathrm{Z}=2)$ space group. The tetragonal $I 4 / m$ structure is derived from 
the prototype $F m \overline{3} m$ cubic structure by an antiphase tilt of the $\mathrm{FeO}_{6}$ and $\mathrm{B}^{\prime \prime} \mathrm{O}_{6}$ octahedra in the basal plane along the [001] direction of the cubic cell. This corresponds to the $a^{0} a^{0} c^{-}$Glazer's notation as derived by Woodward. ${ }^{24}$ The monoclinic $P 2_{1} / n$ structure results from an in-phase and antiphase tilts of the $\mathrm{FeO}_{6}$ and $\mathrm{B}^{\prime \prime} \mathrm{O}_{6}$ octahedra along the [001] direction and in the basal plane of the pseudocubic cell, respectively. This corresponds to the $a^{-} a^{-} c^{+}$Glazer's notation.

As it is reported in Ref. 20, due to the 1:1 order characteristics of the $\mathrm{A}_{2} \mathrm{~B}^{\prime 2+} \mathrm{B}^{\prime \prime 6+} \mathrm{O}_{6}$ double perovskites, which intercalates strongly $\mathrm{B}^{\prime \prime 6+} \mathrm{O}_{6}$ and weakly $\mathrm{B}^{\prime 2+} \mathrm{O}_{6}$ bonded octahedra, only the internal modes of the $\mathrm{B}^{\prime \prime 6+} \mathrm{O}_{6}$ octahedron have to be considered from a vibrational point of view. This is a very interesting structural arrangement because it allows the investigation of the internal modes of the $\mathrm{B}^{\prime \prime 6+} \mathrm{O}_{6}$, which in simple and disordered perovskites form a network of corner sharing octahedra. In the case of disordered occupation of the B" octahedral symmetry sites for two different cations, a strong vibrational coupling between the two different octahedra may occur. Also, their $\mathrm{B}-\mathrm{O}$ bonds are stronger than those belonging to the 12 -coordinated $\mathrm{A}^{2+}-\mathrm{O}$ units. Based on this simple argument, we assume that the octahedra placed at B" symmetry sites behave approximately as "isolated" groups. In the case of occupational disorder at the $\mathrm{B}^{\prime \prime 6+}$ sites, vibrations originating from both octahedra (twophonon-like behavior ${ }^{21,25}$ ) are possible to be observed.

The method of factor group analysis allows us to determine the distribution of the zone-center phonons in the terms of the respective optical-active irreducible representations of $C_{2 h}$ and $C_{4 h}$ point groups. By considering the internal modes of the $\mathrm{B}^{\prime \prime 6+} \mathrm{O}_{6}$ octahedron, the following distributions are obtained: ${ }^{20}$

$$
\begin{aligned}
\Gamma(I 4 / m)= & 6 T\left(2 A_{\mathrm{u}}+B_{\mathrm{g}}+E_{\mathrm{g}}+2 E_{\mathrm{u}}\right)+2 L\left(A_{\mathrm{g}}+E_{\mathrm{g}}\right) \\
& +\nu_{1}\left(A_{\mathrm{g}}\right)+2 \nu_{2}\left(A_{\mathrm{g}}+B_{\mathrm{g}}\right)+2 \nu_{3}\left(A_{\mathrm{u}}+E_{\mathrm{u}}\right) \\
& +2 \nu_{4}\left(A_{\mathrm{u}}+E_{\mathrm{u}}\right)+2 \nu_{5}\left(B_{\mathrm{g}}+E_{\mathrm{g}}\right)+\nu_{6}\left(E_{\mathrm{u}}\right), \\
\Gamma\left(P 2_{\mathrm{l}} / n\right)= & 21 T\left(3 A_{\mathrm{g}}+8 A_{\mathrm{u}}+3 B_{\mathrm{g}}+7 B_{\mathrm{u}}\right)+6 L\left(3 A_{\mathrm{g}}\right. \\
& \left.+3 B_{\mathrm{g}}\right)+2 \nu_{1}\left(A_{\mathrm{g}}+B_{\mathrm{g}}\right)+4 \nu_{2}\left(2 A_{\mathrm{g}}+2 B_{\mathrm{g}}\right) \\
& +6 \nu_{3}\left(3 A_{\mathrm{u}}+3 B_{\mathrm{u}}\right)+6 \nu_{4}\left(3 A_{\mathrm{u}}+3 B_{\mathrm{u}}\right) \\
& +6 \nu_{5}\left(3 A_{\mathrm{g}}+3 B_{\mathrm{g}}\right)+6 \nu_{6}\left(3 A_{\mathrm{u}}+3 B_{\mathrm{u}}\right) .
\end{aligned}
$$

In Eqs. (2) and (3), $\nu_{1}, \nu_{2}$, and $\nu_{3}$, are related to the $\mathrm{B}^{\prime \prime 6+}-\mathrm{O}$ stretching modes, and $\nu_{4}, \nu_{5}$, and $\nu_{6}$ correspond to the $\mathrm{O}-\mathrm{B}^{\prime \prime 6+}-\mathrm{O}$ bending modes. $T$ and $L$ are translational and librational lattice modes, respectively. The wavenumber of most of the vibrations was determined for several authors. Liegeois-Ducykaerts and Tarte ${ }^{26}$ determined that for cubic compounds, the vibrations $T, \nu_{4}, \nu_{5}, \nu_{2}, \nu_{3}$, and $\nu_{1}$, appear in the following wavenumber ranges, respectively, $<350,305-$ $417,348-446,470-608,580-715$, and $716-847 \mathrm{~cm}^{-1}$. Lavat and Baran ${ }^{27}$ determined that for orthorhombic, tetragonal (pseudocubic) and cubic compounds, the vibrations $\nu_{4}$ and $\nu_{3}$, appear in the 265-454 and 534-674 $\mathrm{cm}^{-1}$ wavenumber range, respectively. Ayala et al. ${ }^{20}$ reported that for

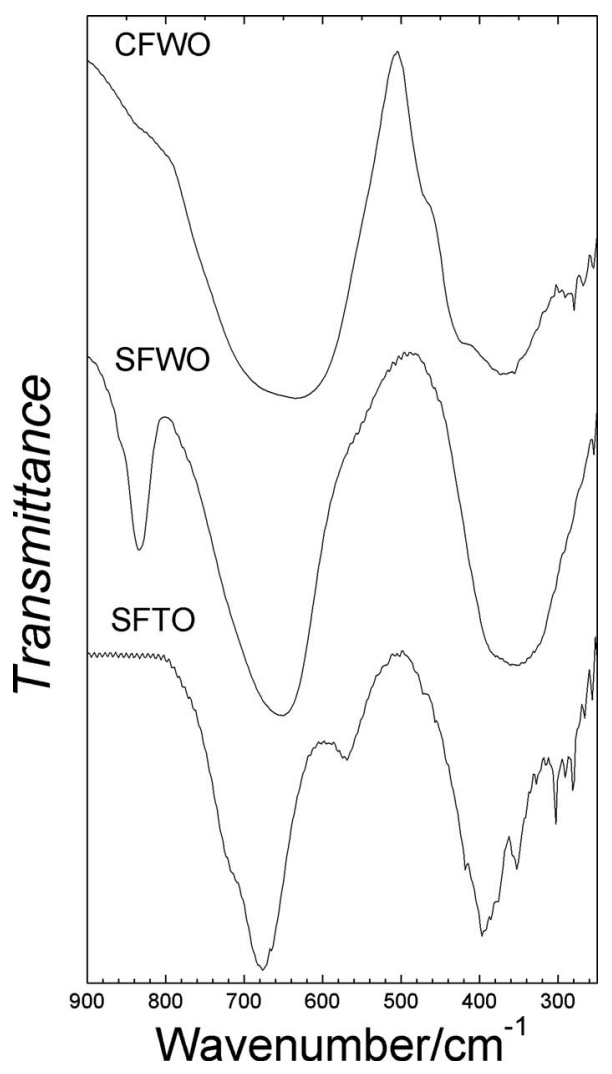

FIG. 2. Room-temperature FTIR spectra of the $\mathrm{A}_{3} \mathrm{Fe}_{2} \mathrm{WO}_{9}(\mathrm{~A}=\mathrm{Sr}, \mathrm{Ca})$ and SFTO double perovskites.

monoclinic and tetragonal compounds, the Raman-active librational modes are in the wavenumber range $190-310 \mathrm{~cm}^{-1}$.

Figure 2 shows, from bottom to top the IR transmittance spectra of SFTO, SFWO and CFWO, respectively. They are very similar to those exhibited for cubic $F m \overline{3} m$ perovskites. This is due to the fact that the tetragonal and monoclinic distortions are very small as shown in Table I.

In Ref. 21, we obtained the IR spectra of the cubic $\mathrm{Ba}_{3} \mathrm{In}_{2} \mathrm{UO}_{9}$ (BIUO) and $\mathrm{Ba}_{3} \mathrm{In}_{2} \mathrm{WO}_{9}$ (BIWO) perovskites. They consist of three strong IR bands at 293, 371, and $603 \mathrm{~cm}^{-1}$ for BIUO and at 299, 360, and $653 \mathrm{~cm}^{-1}$ for BIWO. Following the assignment given in Ref. 21, the bands at 293 (299), 371(360), and 603(653) $\mathrm{cm}^{-1}$ for BIUO (BIWO) were assigned to the translational, $\nu_{4}$ and $\nu_{3}$ modes of the $\mathrm{B}^{\prime \prime 6+} \mathrm{O}_{6}$ octahedron. Here, we observe two strong absorption bands between $300-400 \mathrm{~cm}^{-1}$ and $600-700 \mathrm{~cm}^{-1}$ corresponding to the $\nu_{4}$ and $\nu_{3}$ modes, respectively.

For SFTO, these bands split at least in two narrower components $\left(2 \nu_{4}\right.$ and $\left.2 \nu_{3}\right)$. This is in agreement with the group theory analysis for the tetragonal $I 4 / \mathrm{m}$ space group [see Eq. (2)]. The reason why we do not observe similar splitting for SFWO can be related to the degree of octahedral distortion given by Eq. (1). From Table I, we observe that the SFTO exhibits the largest octahedral distortion $(\Delta \mathrm{d})$. The band appearing at $565 \mathrm{~cm}^{-1}$ may result from either combination $\left(280+290 \mathrm{~cm}^{-1}\right)$ or overtones $(\sim 2 \times 280$ and $\sim 2$ $\left.\times 290 \mathrm{~cm}^{-1}\right)$ of the condensed lattice modes.

In the IR spectra of SFWO and CFWO an additional band around $830 \mathrm{~cm}^{-1}$ is observed. This band is probably 


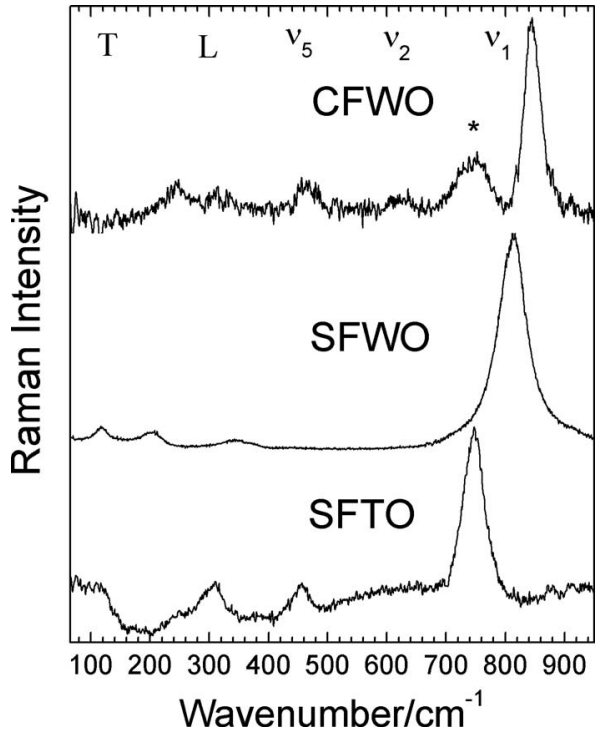

FIG. 3. Room-temperature Raman spectra of the $\mathrm{A}_{3} \mathrm{Fe}_{2} \mathrm{WO}_{9}(\mathrm{~A}=\mathrm{Sr}, \mathrm{Ca})$ and SFTO double perovskites. The asterisk shows $\mathrm{Fe}(\mathrm{III}) \mathrm{O}_{6}$ stretching induced by the occupational disorder.

due to the $\mathrm{WO}_{6}$ symmetric stretching $\left(\nu_{1}\right)$ mode which is very intense in the Raman spectrum, as can be seen in Fig. 3. The appearance of these unexpected bands is likely to be related with a disordered-induced local symmetry lowering, which gives rise to a local loss of the inversion center and allows the $\nu_{1}$ Raman-active mode to become IR-active.

Figure 3 shows, from bottom to top, the unpolarized Raman spectra of SFTO, SFWO, and CFWO, respectively. They are also very similar to those exhibited by the cubic $F m \overline{3} m$ perovskites. The Raman-active phonons of cubic $F m \overline{3} m$ perovskites are $\mathrm{A}_{1 \mathrm{~g}}\left(\nu_{1}\right)+\mathrm{E}_{\mathrm{g}}\left(\nu_{2}\right)+2 \mathrm{~F}_{2 \mathrm{~g}}\left(T, \nu_{5}\right)$. The highest wavenumber appearing in the Raman spectrum ( $\nu$ $>700 \mathrm{~cm}^{-1}$ ) is assigned to $\nu_{1}$, that appearing in the range of $470-650 \mathrm{~cm}^{-1}$ is assigned to $\nu_{2}$, that appearing in the range of $350-450 \mathrm{~cm}^{-1}$ is assigned to $\nu_{5}$, and that appearing in the range of $100-150 \mathrm{~cm}^{-1}$ is assigned to $T$. However, the $\nu_{2}$ mode is missing in most of cubic double perovskites studied in Ref. 20. In Ref. 20 we obtained the Raman spectra of tetragonal and monoclinic $\mathrm{A}_{2} \mathrm{~B}^{\prime 2+} \mathrm{B}^{\prime \prime 6+} \mathrm{O}_{6}$ double perovskites. They also resemble those of cubic $F m \overline{3} m$ perovskites. This evidences that the tetragonal, orthorhombic, and even monoclinic structures result from very small distortions of the cubic cell. Taking into account the discussion presented in Refs. 20, 21, 26, and 27, we list in Table II the Raman and IR wavenumbers as well as their tentative assignment.

The Raman spectrum for monoclinic CFWO presents a band at around $760 \mathrm{~cm}^{-1}$. Since the CFWO exhibits an intrinsic occupational disorder at $2 b$ symmetry sites $\left(\mathrm{Ca}_{2}\left[\mathrm{Fe}_{0.73} \mathrm{~W}_{0.27}\right]^{2 \mathrm{a}}\left[\mathrm{Fe}_{0.60} \mathrm{~W}_{0.40}\right]^{2 \mathrm{~b}} \mathrm{O}_{6}\right)$, this band is likely to be related to the $\nu_{1}$ vibration of the $\mathrm{FeO}_{6}$ octahedron, evidencing a two-phonon-like behavior. ${ }^{21,25}$ The $\nu_{1}\left(\mathrm{FeO}_{6}\right)$ vibration has been observed at around $710 \mathrm{~cm}^{-1}$ for $\mathrm{CaFeO}_{3}$ and $\mathrm{La}_{0.33} \mathrm{Sr}_{0.67} \mathrm{FeO}_{3}$ compounds, as reported by Ghosh et $a l^{28}$

We observe that the difference between the $\nu_{1}$ vibration of SFWO and SFTO is approximately $65 \mathrm{~cm}^{-1}$. Such a difference is related to the chemical nature of hexavalent Te or $\mathrm{W}$ cations. While the $\mathrm{Te}^{6+}$ cation has a fully occupied $d^{10}$ orbital configuration, the $\mathrm{W}^{6+}$ cation has a $d^{0}$ orbital configuration. So, the increase in the wavenumber of the $\nu_{1}$ vibration is correlated with increase of the force constant of the $\mathrm{B}^{\prime \prime 6+}-\mathrm{O}$ bond due to the overlapping of $\mathrm{t}_{2 \mathrm{~g}}$ orbitals of $\mathrm{W}^{6+}$ cation. $^{20,26}$

TABLE II. Optical phonons (in $\mathrm{cm}^{-1}$ ) of SFTO, CFWO, and SFWO.

\begin{tabular}{|c|c|c|c|c|c|c|}
\hline \multicolumn{2}{|c|}{ SFTO $(I 4 / m)$} & \multicolumn{2}{|c|}{ SFWO $(I 4 / m)$} & \multicolumn{2}{|c|}{ CFWO $\left(P 2_{1} / n\right)$} & \multirow[b]{2}{*}{ Assign. } \\
\hline Raman & IR & Raman & IR & Raman & IR & \\
\hline \multirow[t]{3}{*}{746} & & 815 & & 844 & & $\nu_{1}$ \\
\hline & 720 & & 651 & & 632 & $\nu_{3}$ \\
\hline & $676 s$ & & & & & $\nu_{3}$ \\
\hline$\cdots$ & & $\cdots$ & & 620 & & $\nu_{2}$ \\
\hline \multirow[t]{7}{*}{454} & & $\cdots$ & & 465 & & $\nu_{5}$ \\
\hline & $397 \mathrm{~s}$ & & 352 & & 460 & $\nu_{4}$ \\
\hline & 352 & & & & 421 & $\nu_{4}$ \\
\hline & & & & & $372 s$ & $\nu_{4}$ \\
\hline & & 370 & & & & Lattice \\
\hline & & 344 & & & & Lattice \\
\hline & & & & 320 & & Lattice \\
\hline \multirow[t]{6}{*}{309} & & & & & & Lattice \\
\hline & & & & & & Lattice \\
\hline & 300 & & & & & Lattice \\
\hline & 290 & & & & & Lattice \\
\hline & 280 & & & 274 & 279 & Lattice \\
\hline & & & & & 267 & Lattice \\
\hline \multirow[t]{3}{*}{254} & & & 255 & & 254 & Lattice \\
\hline & & & 238 & 245 & 242 & Lattice \\
\hline & & 205 & & & & Lattice \\
\hline$\cdots$ & & 117 & & $\cdots$ & & Lattice \\
\hline
\end{tabular}




\section{CONCLUSIONS}

In this investigation, the IR and Raman spectra of a series of complex double perovskites of the type $\mathrm{A}_{3} \mathrm{Fe}_{2} \mathrm{~B}^{\prime \prime} \mathrm{O}_{9}$ have been recorded and analyzed. Typical internal modes are observed, two $\left(\nu_{3}\right.$ and $\left.\nu_{4}\right)$ IR and three $\left(\nu_{1}, \nu_{2}\right.$, and $\left.\nu_{5}\right)$ Raman modes. Observation of fewer modes than formally predicted by Eqs. (2) and (3) evidences the fact that both the tetragonal and monoclinic structures result from small distortion of the prototype $F m \overline{3} m$ cubic structure. The presence of a $\nu_{1}$-like vibration of the $\mathrm{FeO}_{6}$ octahedron reflects the occurrence of a two-phonon-like behavior due to the intrinsic occupational disorder at octahedral symmetry sites.

\section{ACKNOWLEDGMENTS}

Three of the authors (A.P.A, I.G., and E.N.S.) acknowledge the financial support from CNPq, CAPES, FUNCAP and FAPEMA. C.A.L. acknowledges CONICET for one fellowship. J. C. P. thanks ANPCyT (Project No. PICT 25459), SECyT-UNSL (Project No. 7707), and CONICET (Grant No. PIP No. 6246). J. C. P. is member of CONICET.

${ }^{1}$ K. L. Kobayashi, T. Kimura, H. Sawada, K. Terakura, and Y. Tokura, Nature (London) 395, 357 (1998).

${ }^{2}$ S. A. Ivanov, S.-G. Eriksson, R. Tellgren, and H. Rundlof, Mater. Res. Bull. 36, 2585 (2001).

${ }^{3}$ S. A. Ivanov, S.-G. Eriksson, R. Tellgren, and H. Rundlof, J. Solid State Chem. 178, 3605 (2005).

${ }^{4}$ S. A. Ivanov, P. Nordblad, S.-G. Eriksson, R. Tellgren, and H. Rundlof, Mater. Res. Bull. 42, 776 (2007).

${ }^{5}$ M. S. Augsburger, M. C. Viola, J. C. Pedregosa, R. E. Carbonio, and J. A. Alonso, J. Mater. Chem. 16, 4235 (2006).

${ }^{6}$ M. C. Viola, Sintesis, Determinacion estructural, propiedades magnéticas y de magnetotrasnporte de perovskitas $\mathrm{A}_{3} \mathrm{~B}_{2}^{\prime} \mathrm{B}^{\prime \prime} \mathrm{O}_{9}$ y $\mathrm{A}_{2} \mathrm{~B}^{\prime} \mathrm{B}^{\prime \prime} \mathrm{O}_{6}$ com $\mathrm{A}$ $=\mathrm{Sr}, \mathrm{Ca} ; \mathrm{B}^{\prime}=\mathrm{Fe}$, Co y $\mathrm{B}^{\prime \prime}=\mathrm{Mo}$, W y Te, Doctoral thesis, Universidad Nacional de San Luis - San Luis-Argentina (2004).

${ }^{7}$ L. A. Baum, S. J. Stewart, R. C. Mercader, and J. M. Grenèche, Hyperfine Interact. 156/157, 157 (2004).
${ }^{8}$ A. S. Bhalla, R. Guo, and R. Roy, Mater. Res. Innovations 4, 3 (2000).

${ }^{9}$ A. Dias, F. M. Matinaga, and R. L. Moreira, J. Phys. Chem. B 113, 9749 (2009).

${ }^{10}$ C. Meneghini, F. Sugata Ray, F. Liscio, F. Bardelli, S. Mobilio, and D. D. Sarma, Phys. Rev. Lett. 103, 046403 (2009).

${ }^{11}$ C. J. Howard, B. J. Kennedy, and P. M. Woodward, Acta Crystallogr., Sect. B: Struct. Sci. 59, 463 (2003).

${ }^{12}$ M. C. Viola, M. J. Martínez-Lope, J. A. Alonso, P. Velasco, J. L. Martínez, J. C. Pedregosa, R. E. Carbonio, and M. T. Fernández-Díaz, Chem. Mater. 14, 812 (2002).

${ }^{13}$ M. S. Augsburger, M. C. Viola, J. C. Pedregosa, A. Múñoz, J. A. Alonso, and R. E. Carbonio, J. Mater. Chem. 15, 993 (2005).

${ }^{14}$ J. T. Rijssenbeek, S. Malo, V. Caignaert, and K. R. Poeppelmeier, J. Am. Chem. Soc. 124, 2090 (2002).

${ }^{15}$ J. T. Rijssenbeek, T. Saito, S. Malo, M. Azuma, M. Takano, and K. R. Poeppelmeier, J. Am. Chem. Soc. 127, 675 (2005).

${ }^{16}$ A. J. Jacobson, B. M. Collins, and B. E. F. Fender, Acta Crystallogr., Sect. B: Struct. Sci. 32, Part 4, 1083 (1976).

${ }^{17}$ A. Dias, R. G. Sá, and R. L. Moreira, J. Raman Spectrosc. 39, 1805 (2008).

${ }^{18}$ A. Dias, G. Subodh, M. T. Sebastian, M. M. Lage, and R. L. Moreira, Chem. Mater. 20, 4347 (2008)

${ }^{19}$ A. Dias, L. Abdul Khalam, M. T. Sebastian, M. M. Lage, F. M. Matinaga, and R. L. Moreira, Chem. Mater. 20, 5253 (2008).

${ }^{20}$ A. P. Ayala, I. Guedes, E. N. Silva, M. S. Augsburger, M. C. Viola, and J. C. Pedregosa, J. Appl. Phys. 101, 123511 (2007).

${ }^{21}$ E. N. Silva, A. P. Ayala, I. Guedes, S. A. Larregola, R. M. Pinacca, M. C. Viola, and J. C. Pedregosa, J. Raman Spectrosc 40, 1028 (2009).

${ }^{22}$ M. Retuerto, J. A. Alonso, M. J. Martínez-Lope, M. García-Hernández, C. A. López, M. del C. Viola, J. C. Pedregosa, and M. T. Fernández-Díaz, Eur. J. Inorg. Chem. 2009(25), 3750 (2009).

${ }^{23}$ J. A. Alonso, M. J. Martinez-Lope, M. T. Casais, and M. T. FernandezDiaz, Inorg. Chem. 39, 917 (2000).

${ }^{24}$ P. M. Woodward, Acta Crystallogr., Sect. B: Struct. Sci. 53, 32 (1997).

${ }^{25}$ M. R. Moura, A. P. Ayala, I. Guedes, M. Grimsditch, C. K. Loong, and L. A. Boatner, J. Appl. Phys. 95, 1148 (2004).

${ }^{26}$ M. Liegeois-Duyckaerts and P. Tarte, Spectrochimica Acta A30, 1771 (1974).

${ }^{27}$ A. E. Lavat and E. J. Baran, Vib. Spectrosc. 32, 167 (2003).

${ }^{28}$ S. Ghosh, N. Kamaraju, M. Seto, A. Fujimori, Y. Takeda, S. Ishiwata, S. Kawasaki, M. Azuma, M. Takano, and A. K. Sood, Phys. Rev. B 71, 245110 (2005). 